\title{
Comparison of neuroprotective effects of erythropoietin (EPO) and carbamylerythropoietin (CEPO) against ischemia-like oxygen-glucose deprivation (OGD) and NMDA excitotoxicity in mouse hippocampal slice cultures
}

\author{
Maria Montero $^{\mathrm{a}, *}$, Frantz Rom Poulsen ${ }^{\mathrm{a}}$, Jens Noraberg ${ }^{\mathrm{a}}$, Agnete Kirkeby ${ }^{\mathrm{b}}$, Johan van Beek ${ }^{\mathrm{b}}$, \\ Marcel Leist ${ }^{\mathrm{b}, \mathrm{c}}$, Jens Zimmer ${ }^{\mathrm{a}}$ \\ ${ }^{a}$ Department of Anatomy and Neurobiology, Institute of Medical Biology, University of Southern Denmark, Winsløwparken 21 st, DK-5000 Odense C, Denmark \\ ${ }^{\mathrm{b}}$ Disease Biology, H. Lundbeck A/S, Valby, Denmark \\ ${ }^{\mathrm{c}}$ Faculty of Biology, University of Konstanz, Konstanz, Germany
}

\begin{abstract}
In addition to its well-known hematopoietic effects, erythropoietin (EPO) also has neuroprotective properties. However, hematopoietic side effects are unwanted for neuroprotection, underlining the need for EPO-like compounds with selective neuroprotective actions. One such compound, devoid of hematopoietic bioactivity, is the chemically modified, EPO-derivative carbamylerythropoietin (CEPO). For comparison of the neuroprotective effects of CEPO and EPO, we subjected organotypic hippocampal slice cultures to oxygen-glucose deprivation (OGD) or $\mathrm{N}$-methyl-D-aspartate (NMDA) excitotoxicity. Hippocampal slice cultures were pretreated for $24 \mathrm{~h}$ with $100 \mathrm{IU} / \mathrm{ml} \mathrm{EPO}(=26 \mathrm{nM})$ or $26 \mathrm{nM}$ CEPO before OGD or NMDA lesioning. Exposure to EPO and CEPO continued during OGD and for the next $24 \mathrm{~h}$ until histology, as well as during the $24 \mathrm{~h}$ exposure to NMDA. Neuronal cell death was quantified by cellular uptake of propidium iodide (PI), recorded before the start of OGD and NMDA exposure and $24 \mathrm{~h}$ after. In cultures exposed to OGD or NMDA, CEPO reduced PI uptake by $49 \pm 3$ or $35 \pm 8 \%$, respectively, compared to lesion-only controls. EPO reduced PI uptake by $33 \pm 5$ and $15 \pm 8 \%$, respectively, in the OGD and NMDA exposed cultures. To elucidate a possible mechanism involved in EPO and CEPO neuroprotection against OGD, the integrity of $\alpha$-II-spectrin cytoskeletal protein was studied. Both EPO and CEPO significantly reduced formation of spectrin cleavage products in the OGD model. We conclude that CEPO is at least as efficient neuroprotectant as EPO when excitotoxicity is modeled in mouse hippocampal slice cultures.
\end{abstract}

(C) 2006 Elsevier Inc. All rights reserved.

Keywords: Organotypic; Glutamate receptors; Calpain; Neuroprotection

\section{Introduction}

EPO is a $34 \mathrm{kDa}$ pleiotropic cytokine with well-known hematopoietic and neuroprotective activities (Sasaki, 2003). EPO was first recognized for its hematopoietic properties, where EPO acts as a growth factor and inhibitor of apoptotic cell death (Fisher, 2003). Binding of EPO to its receptor
(EPOR) in the bone marrow stimulates survival, proliferation and differentiation of erythroid cells. Traditionally, EPO has been seen as a stimulator of hematopoiesis and produced in kidney, liver and spleen in response to hypoxia, but it is also expressed in the uterus (Davis et al., 2003) and in brain (Genc et al., 2004a,b; Sasaki, 2003). In the brain, EPO is highly expressed in development (Buemi et al., 2002; Nagai et al., 2001). In the mature brain, expression of EPO appears to be upregulated by oxidative or nitrosative stress (Bernaudin et al., 1999, 2000; Chong et al., 2003; Digicaylioglu et al., 1995). Within the brain, functional EPORs are expressed by different 
cell types such as neurons, glial cells and brain capillary endothelial cells (Genc et al., 2004a,b), while the main source of EPO within the CNS itself appears to be the astroglial cells (Bernaudin et al., 2000; Digicaylioglu et al., 1995; Juul et al., 1998; Marti et al., 1996; Masuda et al., 1993). Despite its extensive glycosylation and large size, EPO has been shown in multiple experimental species and in man to cross the blood brain barrier (BBB) when administered peripherally (Ehrenreich et al., 2004). During brain development, the expression of both EPO and EPOR changes drastically (Buemi et al., 2005; Genc et al., 2004a,b; Juul et al., 1999). Lately, Ruscher et al. (2002) hypothesized that EPO has paracrine functions in cerebral ischemia. The neuroprotective effects of EPO appear to be mediated by various mechanisms, including decreased production and/or release of tissue-injuring molecules such as reactive oxygen and nitrogen species and glutamate, modulation of neurotransmission, reversal of vasospasm, attenuation of apoptosis and modulation of inflammation (Brines and Cerami, 2005). The mechanisms by which these processes take place, however, are not yet fully elucidated. It has been shown that calcium overload leads to neurodegeneration in cerebral ischemia (Choi, 1995). Excessive calcium levels are responsible for activation of intracellular calcium proteases, such as calpains, which play a pivotal role in cytoskeletal degeneration and ischemic cell death (Saido et al., 1994; Wang and Yuen, 1994). Calpain is a cysteine protease which is overactivated in several pathological conditions, including all forms of excitotoxicity (Azuma et al., 1991; Siman and Noszek, 1988; Wang and Yuen, 1994). One of the substrates of calpain is the cytoskeletal protein non-erythroid $\alpha$-IIspectrin (=fodrin) (Martin et al., 1995). In neuronal cells, $\alpha$ II-spectrin breakdown products (SBDP) of $150 \mathrm{kDa}$ and $145 \mathrm{kDa}$ have been shown to be produced by calpain activation (Nath et al., 1996a,b). MDL 28170, a selective cell-permeant calpain inhibitor, has been shown to be neuroprotective against OGD in rat hippocampal slice cultures (Brana et al., 1999). The main goal of this study was to investigate and compare the neuroprotective effects of EPO and CEPO. Also the latter has been shown to cross the blood brain barrier and may therefore be considered as antiexcitotoxic therapeutic (Leist et al., 2004). For this purpose, we used hippocampal slice cultures, derived from postnatal day 7 mouse and subjected to ischemia-like oxygen-glucose deprivation (OGD) or glutamate receptor-mediated NMDA excitotoxicity.

\section{Materials and methods}

\section{Slice preparation and culturing}

Here 7-day-old C57BL/6J mice were killed by an instant cut of the brain stem, the brain removed and the hippocampi isolated by dissection. Each hippocampus was then cut in transverse sections at $350 \mu \mathrm{m}$ by a Mcllwain tissue chopper. Thereafter the slices were transfer to Gey's balanced salt solution (Gibco Life Technologies, Paisley, UK) with D- glucose $(6.5 \mathrm{mg} / \mathrm{ml})$, trimmed for excess tissue under a microscope and placed randomly on semiporous $(0.4 \mu \mathrm{m}$ pore size) insert membranes (30 $\mathrm{mm}$ in diameter) (Millipore Corp., Bedford, MA, USA, Cat. No. PICM 03050) with 6 slices on each membrane. The inserts with the slices were transferred to six well culture trays (Corning Costar, Corning, NY, USA) with $1 \mathrm{ml}$ of culturing medium in each well and placed in an incubator with $5 \% \mathrm{CO}_{2}$ and $95 \%$ atmospheric air at $33^{\circ} \mathrm{C}$. The culturing medium was composed of 50\% Opti-MEM (Cat. No. 31985-047), 25\% horse serum (Cat. No. 26050-047), 25\% Hank's BBS (HBSS; Cat. No. 24020-091) (all from Gibco BRL), supplemented by D-glucose to a final concentration of $25 \mathrm{mM}$. After 3-4 days, the culture medium was changed twice a week for the next 2 weeks. One day before exposure, the medium was replaced by $1 \mathrm{ml}$ of chemically defined, serumfree Neurobasal medium (Gibco BRL, Cat. No. 21103-049) with $25 \mathrm{mM}$ D-glucose and $1 \mathrm{mM}$ L-glutamine (Sigma, Cat. No. 25030-024) and 2\% B27 supplement (Gibco BRL, Cat. No. 17504-010) and the cultures transferred to an incubator at $36^{\circ} \mathrm{C}$. No antimitotic drugs or antibiotics were used at any stages.

\section{Drug delivery}

EPO (26 nM) and CEPO (26 nM) (generously provided by Lundbeck A/S) were added to the culture medium $24 \mathrm{~h}$ prior to oxygen-glucose deprivation or NMDA exposure and to all media used up to the histological processing.

\section{Induction of in vitro ischemia}

For oxygen-glucose deprivation (OGD), a submersion protocol introduced by Frantseva et al. (1999) and modified by Bonde et al. (2002) was used. The OGD medium used for submersion was an artificial cerebrospinal fluid (ACSF) with the following composition: $120 \mathrm{mM} \mathrm{NaCl}, 5 \mathrm{KCl}$, $1.25 \mathrm{mM} \mathrm{NaH} \mathrm{PO}_{4} \cdot \mathrm{H}_{2} \mathrm{O}, 2 \mathrm{mM} \mathrm{MgSO}_{4} \cdot 7 \mathrm{H}_{2} \mathrm{O}, 2 \mathrm{mM}$ $\mathrm{CaCl}_{2}, 25 \mathrm{mM} \mathrm{NaHCO}, 20 \mathrm{mM}$ HEPES and $25 \mathrm{mM}$ sucrose. The ACSF was bubbled with a gas mixture containing $5 \% \mathrm{CO}_{2}$ and $95 \% \mathrm{~N}_{2}$, resulting in an $\mathrm{O}_{2}$ gas pressure measured to be close to zero. After a single wash of the culture well with the OGD medium, $1 \mathrm{ml}$ of this medium was placed below and $1 \mathrm{ml}$ on top of the semiporous membranes, covering the hippocampal slices. The culture trays were then wrapped in airtight plastic foil and placed in the incubator at $36^{\circ} \mathrm{C}$ for $30 \mathrm{~min}$, known from previous experiments to induce $50 \%$ cell death in hippocampal CA1 pyramidal cells (see below). Control cultures consisted of cultures handled and submersed in the same way as OGD cultures, but using ACSF with $25 \mathrm{mM}$ glucose instead of sucrose (sham-OGD cultures), and cultures not manipulated at any time (controls). After OGD, submersed OGD and sham-OGD cultures were washed once with Neurobasal, transferred to cultures trays with Neurobasal medium and returned to the $\mathrm{CO}_{2}$ incubator at $36^{\circ} \mathrm{C}$, where they remained for $24 \mathrm{~h}$ more until fixation in $4 \%$ paraformaldehyde (PFA) and histological processing. 


\section{NMDA dose-response in mouse hippocampal slice cultures} CA1

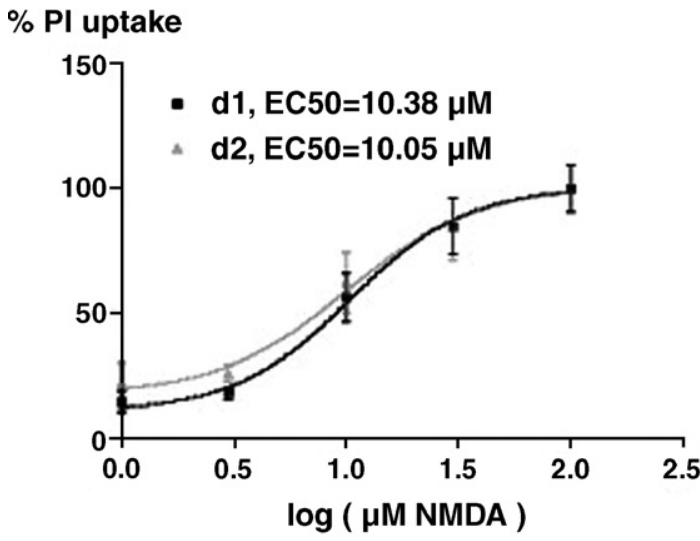

Fig. 1. Dose-response curve for NMDA-induced excitotoxic neurodegeneration in 14-day-old hippocampal slice cultures, derived from 7-day-old mice. Neuronal cell death in the CA1 pyramidal cell layer was monitored by densitometric measurements of the cellular uptake of propidium iodide (PI). PI uptake was assessed $24 \mathrm{~h}$ after NMDA exposure. Maximal PI uptake recorded at the highest NMDA dose was set up to $100 \%$ cell death. The $\mathrm{EC}_{50}$ value for the CA1 pyramidal cell layer was found to be $10 \mu \mathrm{M}$.

Determination of the $E T_{50}$ value for $O G D$ in mouse hippocampal slice cultures

In initial studies, two-week-old hippocampal slice cultures were exposed to OGD for 10, 20, 30, 45, 60, 90 and $120 \mathrm{~min}$ and the neuronal damage assessed by PI uptake after $24 \mathrm{~h}$. In order to determine the time needed to induce $50 \%$ neuronal cell death ( $\mathrm{ET}_{50}$ value) among CA1 pyramidal neurons, as determined by cellular uptake of propidium iodide, the $\mathrm{ET}_{50}$ value was in this way found to be $30 \mathrm{~min}$ (data not shown).

\section{Determination of the $E C_{50}$ value for NMDA in mouse hippocampal slice cultures}

Two-week-old hippocampal slice cultures were exposed to increasing concentrations of $\operatorname{NMDA}(1,3,10,30,100 \mu \mathrm{M})$. In order to determine the concentration needed to induce $50 \%$ neuronal cell death among CA1 pyramidal cells, as determined by propidium iodide uptake, the $\mathrm{EC}_{50}$ value for NMDA was in this way found to be $10 \mu \mathrm{M}$ (Fig. 1).

Quantification by cellular uptake of propidium iodide (PI) as a marker of cell death

Cell death was determined by the fluorescence cell death indicator propidium iodide (PI) (Sigma). PI was added to the medium $24 \mathrm{~h}$ before OGD of control and experimental cultures to yield a $2 \mu \mathrm{M}$ concentration. Recordings of cellular PI uptake by fluorescence microphotographs were performed immediately before the hypoxic or the excitotoxic insult and $24 \mathrm{~h}$ after using a tetramethyl rhodamine isothiocyanate filter (510-560/ $590 \mathrm{~nm}$ ) and a Sensys KAF 1400 G2 (Photometrics, Tucson, AZ) digital camera (Noraberg et al., 1999). Correspondingly, timed recordings were performed from the respective controls. The PI uptake in the cell layers of the different hippocampal subfields (CA1, CA3, dentate gyrus and all entire hippocampus) was quantified densitometrically, using NIH Image software (version 1.64).

Oxygen-glucose deprivation (OGD) experimental protocol

For induction of neuronal cell death by oxygen and glucose deprivation and test of neuroprotective effects of EPO and CEPO, hippocampal slice cultures from newborn (P7) C57BL/6J mice grown for 2 weeks in a $5 \% \mathrm{CO}_{2}$ incubator were treated according to the experimental protocol described below. Twenty-four hours before exposing the cultures to OGD, the serum-containing medium where the cultures were grown for 14 days in vitro was replaced by Neurobasal medium containing the cell death marker PI. For tests of the neuroprotective effects of EPO and CEPO, the compounds were added in relation to the medium change $24 \mathrm{~h}$ before the ischemic insult and maintained in Neurobasal medium during the subsequent $24 \mathrm{~h}$ recovery period until fixation for histology (Fig. 2A). The EPO and CEPO concentrations used were chosen on the basis of results from other studies

\section{A Experimental OGD protocol}

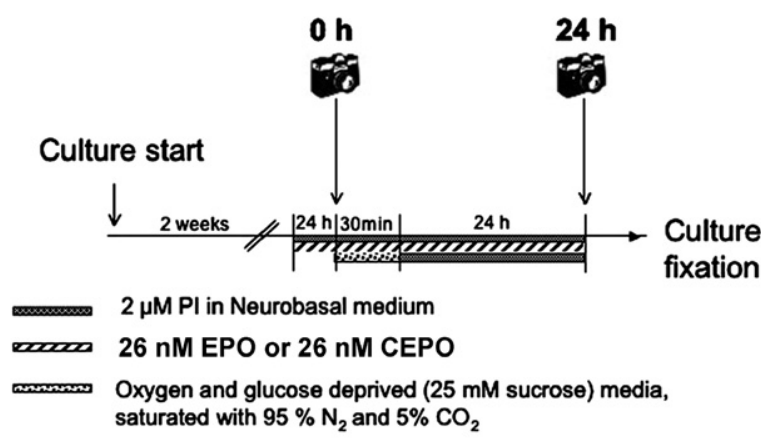

\section{B Experimental NMDA protocol}
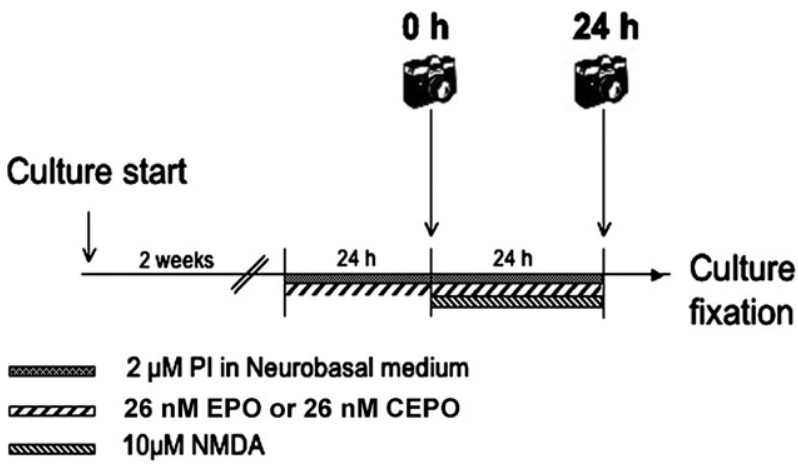

Fig. 2. Schematic representation of the experimental protocols in 14 days old hippocampal slice cultures, derived from 7 days old mice when exposed to (A) oxygen-glucose deprivation and (B) NMDA excitotoxicity with and without the presence of EPO or CEPO. Recordings of induced cellular uptake of PI were performed before the insult $(0 \mathrm{~h})$ and $24 \mathrm{~h}$ post-insult. EPO and CEPO were added to the Neurobasal medium together with PI $24 \mathrm{~h}$ before the lesion and remained in the medium until fixation of the cultures for histology. 
(data not shown). For histological processing, experimental and control cultures were fixed in 4\% PFA and cryoprotected in $20 \%$ sucrose overnight, before sectioned by cryostat in two parallel series of $20 \mu \mathrm{m}$. One series was cell stained by toluidine blue to evaluate general morphology of the hippocampal slice cultures. The other series was immunostained for the microtubule-associated protein 2 (MAP2) to visualize neuronal cytoskeletal integrity (Noraberg et al., 1999). Changes in MAP2 staining were recorded by digital photographs of the whole hippocampus and CA1.

\section{NMDA lesion experimental protocol}

To evaluate the neuroprotective effect of EPO and CEPO against an NMDA-induced excitotoxic lesion, 2-week-old hippocampal slice cultures were exposed to $10 \mu \mathrm{M}$ of NMDA, which is known to induce $50 \%$ neuronal cell death $\left(\mathrm{EC}_{50}\right.$ value) in the CA1 pyramidal cell layer in hippocampal slice cultures from P7 C57BL/6J mouse (Fig. 1). For quantitation of cell death, PI was added to the medium $24 \mathrm{~h}$ before exposing the cultures to the excitotoxic lesion with $10 \mu \mathrm{M}$ of NMDA in relation to a medium change from serum-containing medium to Neurobasal medium. NMDA was present in the medium for $24 \mathrm{~h}$ before histological processing. EPO and CEPO, both in a $26 \mathrm{nM}$ concentration, were added to the medium also $24 \mathrm{~h}$ prior NMDA exposure and were present in the media until the cultures were fixed with 4\% PFA solution and cryoprotected in sucrose (Fig. 2B). For histology, the hippocampal slice cultures were cryostat sectioned in two parallel series of $20 \mu \mathrm{m}$ thick sections. One series was cell stained for toluidine blue, the other for the neuronal cytoskeletal marker MAP2, and digital microphotographs taken of the whole hippocampus and CA1.
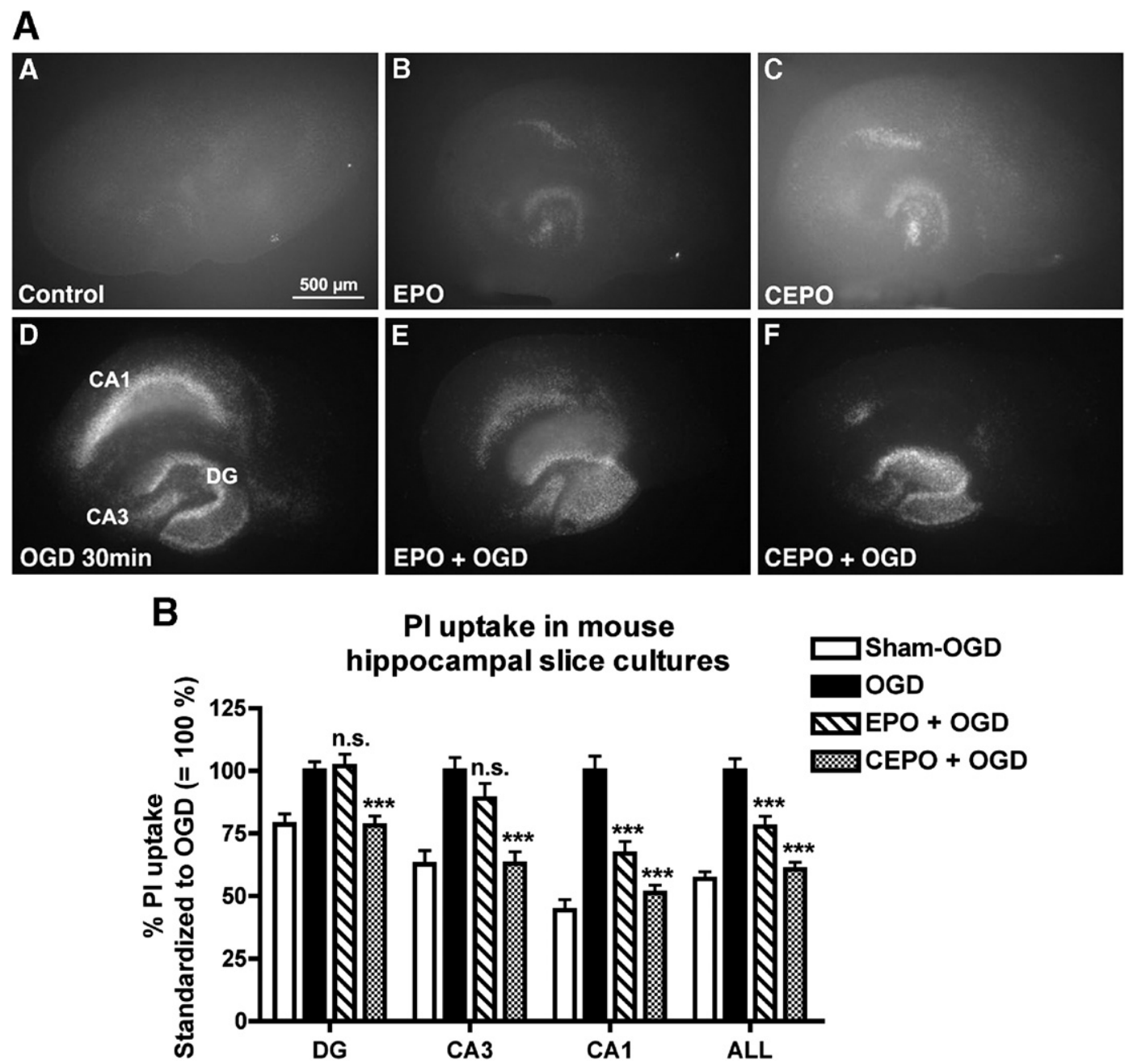

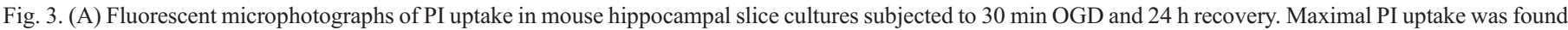

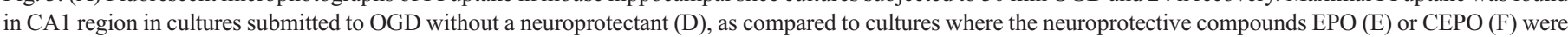

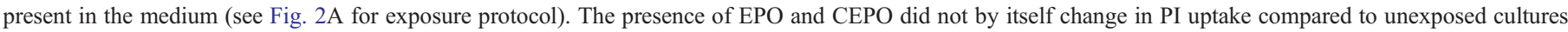

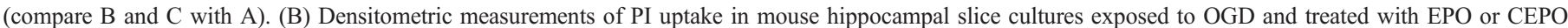

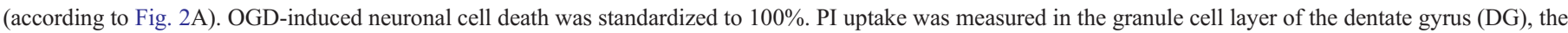

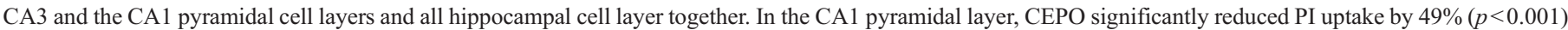

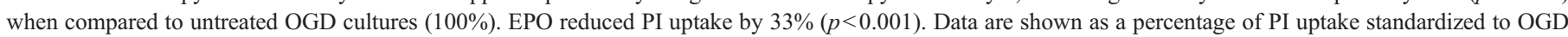
$(n=27-30)$. 
Western blot analysis

Lysates were prepared from 18 pooled slice cultures for each condition. For lysis, the cultures were subjected to three freezethaw cycles in 3-[(3-cholamidopropyl) dimethylammonio]-1propane sulfonate (CHAPS) buffer (50 mM PIPES, $0.1 \%$ CHAPS, 2 mM EDTA, 5 mM DTT; adjusted to $\mathrm{pH}$ 6.5), with addition of a complete protease inhibitor cocktail (Roche) before lysis. Lysates were spun down at $15,000 \times \mathrm{g}$ for $10 \mathrm{~min}$, and supernatants were used for Western blotting. For SDSPAGE, $10 \mu \mathrm{g}$ of protein was loaded per well on a 7\% Trisacetate NuPAGE gel (Invitrogen). For immunoblotting, anti- $\alpha$ II-spectrin antibody from Chemicon (CA, USA, MAB1622, dilution 1:1000) and $\beta$-actin antibody from Sigma (A5441, dilution 1:5000) were used together with horseradish peroxidase-conjugated secondary antibodies (DAKO, Denmark). The blots were developed using the enhanced chemiluminescence system (ECL Western blotting system, Amersham Biosciences). SeeBlue prestained standards (Invitrogen) were included on the blots. Band densities were quantified by the Fuji Film MultiGauge software.

\section{Microtubule-associated protein 2 immunohistochemistry}

Immunohistochemical staining for MAP2 was performed on cryostat sections of PFA-fixed cultures. First, the sections were thawed at room temperature (RT) and washed in Tris buffered saline (TBS), pH 7.4 for 15 min followed by washing in TBS + triton X-100 (Sigma) $3 \times 15 \mathrm{~min}$. After blocking unspecific staining with $10 \%$ fetal bovine serum in TBS (FBS), the sections were incubated for 2 days at $4{ }^{\circ} \mathrm{C}$ with the primary mouse-anti-MAP2 (Sigma) diluted 1:1000 in FBS. The sections were then washed in TBS + triton X-100, $3 \times 15 \mathrm{~min}$, and incubated for $1 \mathrm{~h}$ at RT with the secondary biotinylated

\section{A}
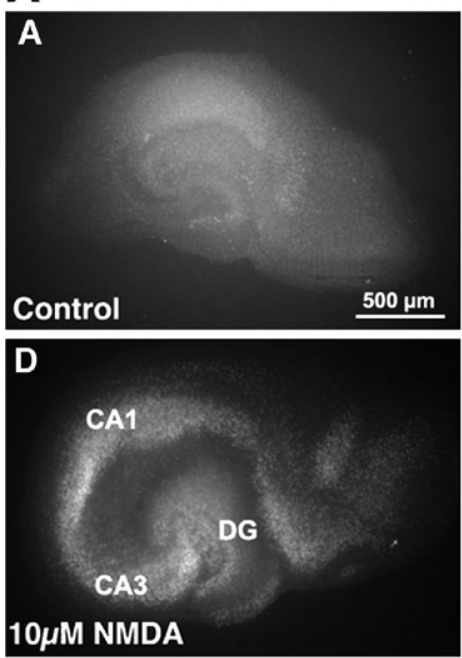

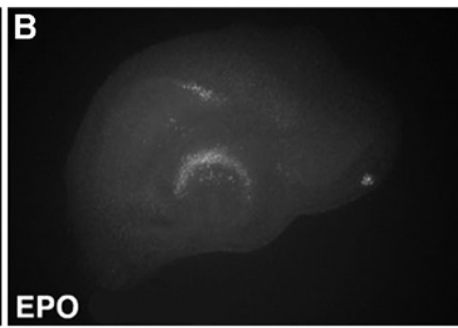

E

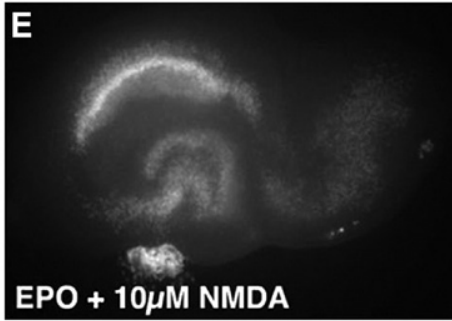

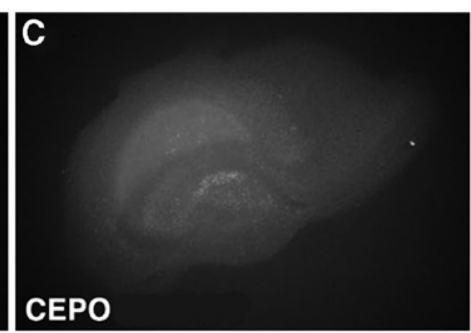

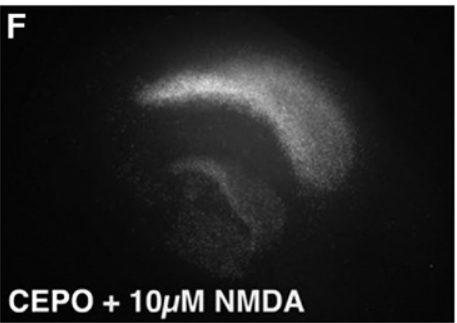

B

PI uptake in mouse hippocampal slice cultures
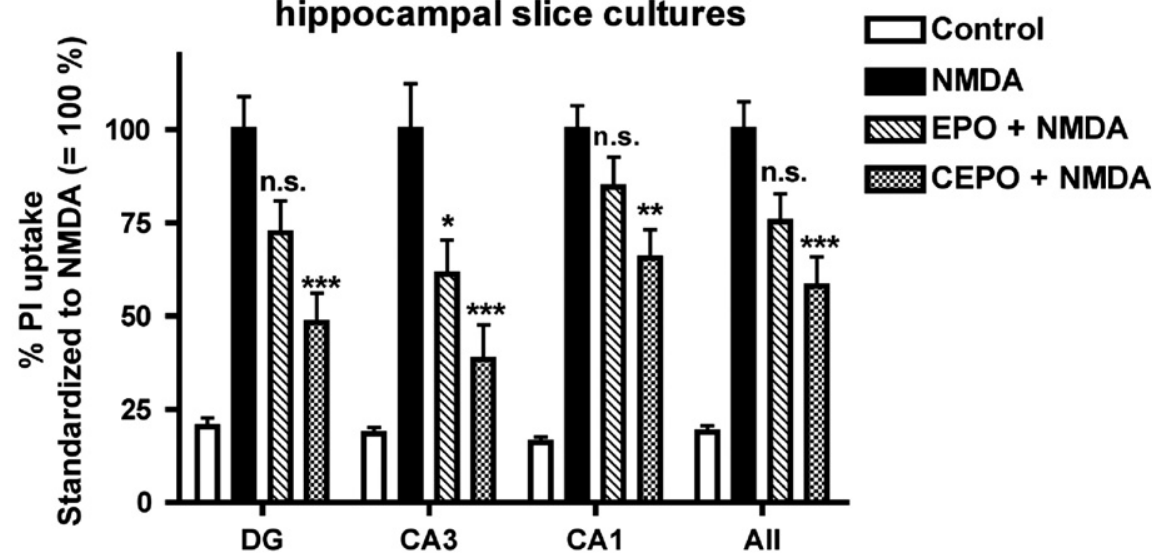
sheep anti-mouse antibody (RNP1001V1, Amersham) diluted 1:200 in FBS. Following a rinse in TBS for $5 \mathrm{~min}$, the sections were washed again in TBS + triton X-100, 3× $15 \mathrm{~min}$, before the incubation with streptavidin-HRP (P0397, DakoCytomation) diluted 1:200 in FBS for $1 \mathrm{~h}$ at RT. The sections were then washed in TBS $3 \times 15 \mathrm{~min}$ and developed in $25 \mathrm{mg}$ of diaminobenzidine (DAB) diluted in $50 \mathrm{ml}$ of FBS and $16.5 \mu \mathrm{l}$ of $\mathrm{H}_{2} \mathrm{O}_{2}$ for $15 \mathrm{~min}$. Finally, the sections were washed in TBS $3 \times 15 \mathrm{~min}$. The sections were then rinsed in distilled water and dehydrated in ethanol $(70 \% 2 \mathrm{~min}, 96 \% 2 \times 2 \mathrm{~min}, 99 \%$ $3 \times 2 \mathrm{~min}$ ) cleared in xylene $3 \times 5 \mathrm{~min}$ and coverslipped with DePex mounting media.

\section{General toluidine blue cell staining}

For histological evaluation of the hippocampal slice cultures, toluidine blue (Merck) staining was performed on cryostat sections previously fixed in 4\% PFA and cryoprotected in $20 \%$ sucrose. First, the sections were thawed at RT for $30 \mathrm{~min}$. The sections were then washed in Tris buffered saline, $\mathrm{pH}$ 7.4 (TBS) for $15 \mathrm{~min}$ followed by rinsing in distilled water for $2 \mathrm{~min}$. The TB solution was previously filtered before being used. Once filtered, the sections were incubated in the TB solution for $10 \mathrm{~min}$ followed by $3 \times 5 \mathrm{~min}$ washes in distilled water to get rid of the excess of TB solution. Thereafter, sections were dehydrated in $99 \%$ ethanol $3 \times 5 \mathrm{~min}$. Finally, sections were cleared in xylene $3 \times 5 \mathrm{~min}$ and coverslipped with DePex mounting media.

\section{Statistical analysis}

Densitometric measurements of PI uptake were expressed as mean \pm SEM, and differences of $p<0.05$ were considered significant. Statistical significance was determined by using ANOVA followed by Bonferroni's post hoc analysis of relevant experimental groups.

\section{Results}

\section{OGD-induced PI uptake and effects of EPO and CEPO}

Based on the densitometric measurements of cellular PI uptake recorded $24 \mathrm{~h}$ after $30 \mathrm{~min}$ of OGD, the CA1 pyramidal cell layer of the hippocampus was more susceptible than the corresponding cell layer in CA3 (PI uptake in arbitrary units:

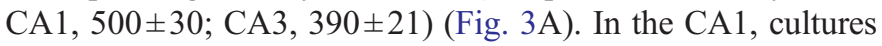
exposed to OGD in the presence of EPO showed a $33 \%$ reduction of PI uptake (PI uptake in arbitrary units: $336 \pm 24$ ), compared to cultures exposed to OGD only $(p<0.001)$. The non-erythropoietic variant CEPO also displayed a powerful protective effect decreasing PI uptake by $49 \%$ (PI values in arbitrary units of $260 \pm 16 ; p<0.001$ ). In the dentate gyrus (DG), OGD cultures exposed to EPO showed no statistical difference compared to OGD-only cultures, while CEPO decreased PI uptake by $22 \%$. With respect to neuroprotective effects of EPO and CEPO, the CA3 pyramidal layer showed similar patterns of PI uptake as the DG. In the CA1 pyramidal cell layer, sham-
OGD cultures displayed a reduction of PI uptake of $56 \%$ compared to OGD-only cultures $(p<0.001)$. PI uptake was virtually absent in non-OGD-exposed control cultures treated with EPO or CEPO (PI uptake in arbitrary units: $1.3 \pm 2$ and $0.7 \pm 1.9$, respectively) (data not shown) (Fig. 3B).

\section{NMDA-induced PI uptake and effects of EPO and CEPO}

Cultures exposed to $10 \mu \mathrm{M}$ NMDA for $24 \mathrm{~h}$ displayed most neuronal cell death, monitored by PI uptake, in the CA1 pyramidal cell layer, but also CA3 and dentate gyrus cell layers displayed significant neurodegeneration (PI uptake in arbitrary units: CA1, 633 \pm 41 ; CA3, $424 \pm 52, \mathrm{DG}, 531 \pm$ 47) (Fig. 4A). Control cultures and non-lesioned cultures exposed to EPO or CEPO showed a low PI uptake in all hippocampal cell layers (data not shown). In the DG of NMDA-lesioned cultures, EPO reduced PI uptake by $28 \%$ (n.s.), while CEPO reduced PI uptake by $52 \%$ compared to non-treated NMDA-lesioned cultures $(p<0.001)$. In the CA3, NMDA-lesioned cultures exposed to EPO or CEPO displayed a reduction in PI uptake by $39 \%(p<0.01)$ and $62 \%(p<0.001)$, respectively. In the CA1, EPO did not significantly decrease NMDA-induced neuronal cell death expressed by PI uptake (PI uptake in arbitrary units: $536 \pm 50$ compared to $633 \pm 41$ in non-treated NMDA-lesioned cultures). In contrast to this, CEPO induced a significant decrease in CA1 neuronal cell death reducing the PI uptake by $35 \%(p<0.001)$ (PI uptake in arbitrary units: $414 \pm 48)$, compared to NMDA-exposed cultures (Fig. 4B).

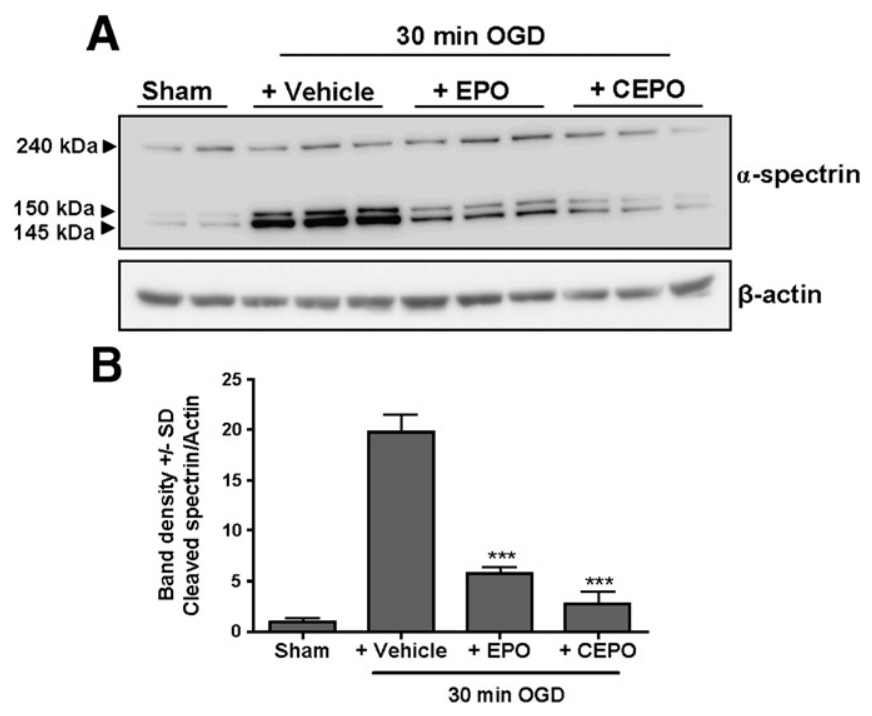

Fig. 5. Hippocampal slice cultures were preincubated for $24 \mathrm{~h}$ with OGD medium (vehicle), EPO (26 nM) or CEPO $(26 \mathrm{nM})$ before $30 \mathrm{~min}$ OGD and collected $24 \mathrm{~h}$ after OGD. Lysates were subjected to Western blotting against $\alpha$-spectrin and $\alpha$-actin. (A) Western blot showing calpain-mediated cleavage of full-length $\alpha$-spectrin $(240 \mathrm{kDa})$ to breakdown products of 145 and $150 \mathrm{kDa}$ after OGD. (B) Quantification of cleaved $\alpha$-spectrin on Western blot. The band densities of $\alpha$-spectrin fragments $145 / 150 \mathrm{kDa}$ were standardized to $\alpha$-actin for each lane. The graph shows the average of triplicate loadings on the gel (duplicate for sham-OGD). Asterisks denote statistically significant differences compared to $\mathrm{OGD}+$ vehicle $(* * * p<0.001)$. 


\section{EPO and CEPO inhibit OGD-induced calpain activation}

In order to investigate whether EPO or CEPO modulated late molecular markers of cell death in OGD-treated slices, the integrity of $\alpha$-II-spectrin after OGD with and without EPO or CEPO was investigated. $\alpha$-II-spectrin is a $240 \mathrm{kDa}$ structural protein, and cleavage to $145 / 150 \mathrm{kDa} \alpha$-II-spectrin products has earlier been shown to be characteristic for calpain-mediated cleavage of the protein during cell death (Nath et al., 1996a,b). Analysis of the patterns of $\alpha$-II-spectrin cleavage in hippocampal slices by Western blotting $24 \mathrm{~h}$ after OGD revealed a significant increase in 145 and $150 \mathrm{kDa} \alpha$-II-spectrin breakdown products indicating an OGD-induced activation of calpain (Fig. 5). Preincubation of the slices with EPO or CEPO significantly reduced the formation of OGD-induced $145 / 150 \mathrm{kDa}$ $\alpha$-II-spectrin cleavage products, suggesting that the neuroprotective actions of EPO and CEPO involve inhibition of calpain activity.

\section{Histological analysis by toluidine blue cell staining}

Toluidine blue cell staining was used to evaluate and qualify the morphology of our hippocampal slice cultures after both the OGD (Figs. 6D-F) and the NMDA-induced lesions (Figs. 7DF). In control not manipulated cultures (Figs. 6D; 7D), the general structural integrity and subfield cell layers were well preserved in all its different subfields. Hippocampal pyramidal cells and granule cells appeared healthy with intact nuclear morphology and chromatin density. Treatment of the cultures with EPO (Fig. 8I) or CEPO (Fig. 8J) did not induce any obvious deleterious effects on cellular morphology in any of the hippocampal regions. OGD-lesioned cultures (Figs. 6E; 8L) displayed a significant increase in the number of pyknotic nuclei $24 \mathrm{~h}$ after OGD. The induction of pyknotic nuclei was stronger and more widespread in NMDA-lesioned cultures (Figs. 7E; 9D). Treatment with EPO reduced in both OGD (Fig. $8 \mathrm{M}$ ) or NMDA-lesioned cultures (Fig. 9E), the number of pyknotic cells. Treatment with CEPO was at least as effective against both OGD (Figs. 6F; 8N) and NMDA (Figs. 7F; 9F).

\section{MAP2 immunoreactivity}

Immunostaining for the microtubule-associated protein 2 (MAP2) was performed on both OGD (Figs. 6A-C; 8A-G) and NMDA treated (Figs. 7A-C; 9A-C) cultures, as a supplement to the observations based on PI uptake and toluidine blue staining. MAP2 is primarily present in dendrites and as such known to be a marker of neuronal structural integrity. Loss of MAP2 immunoreactivity has thus been described as one of the first indicators of neuronal
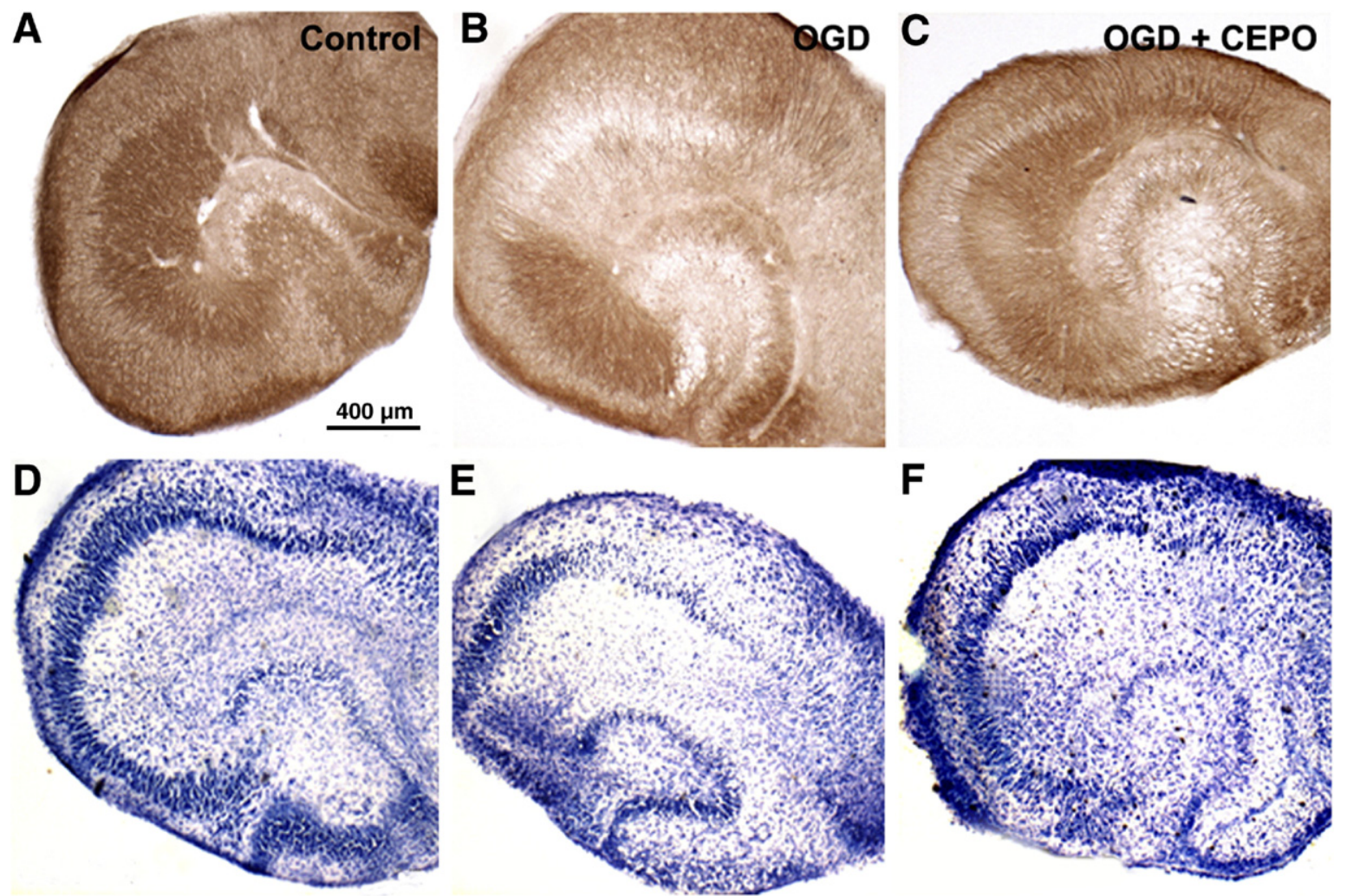

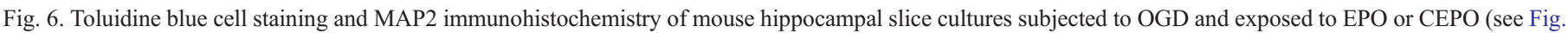

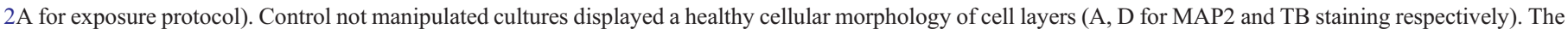

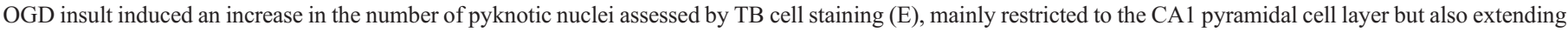

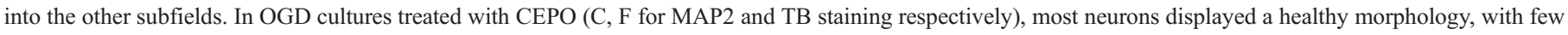
scattered pyknotic nuclei along the CA1 subfield and high density of dendritic processes. 

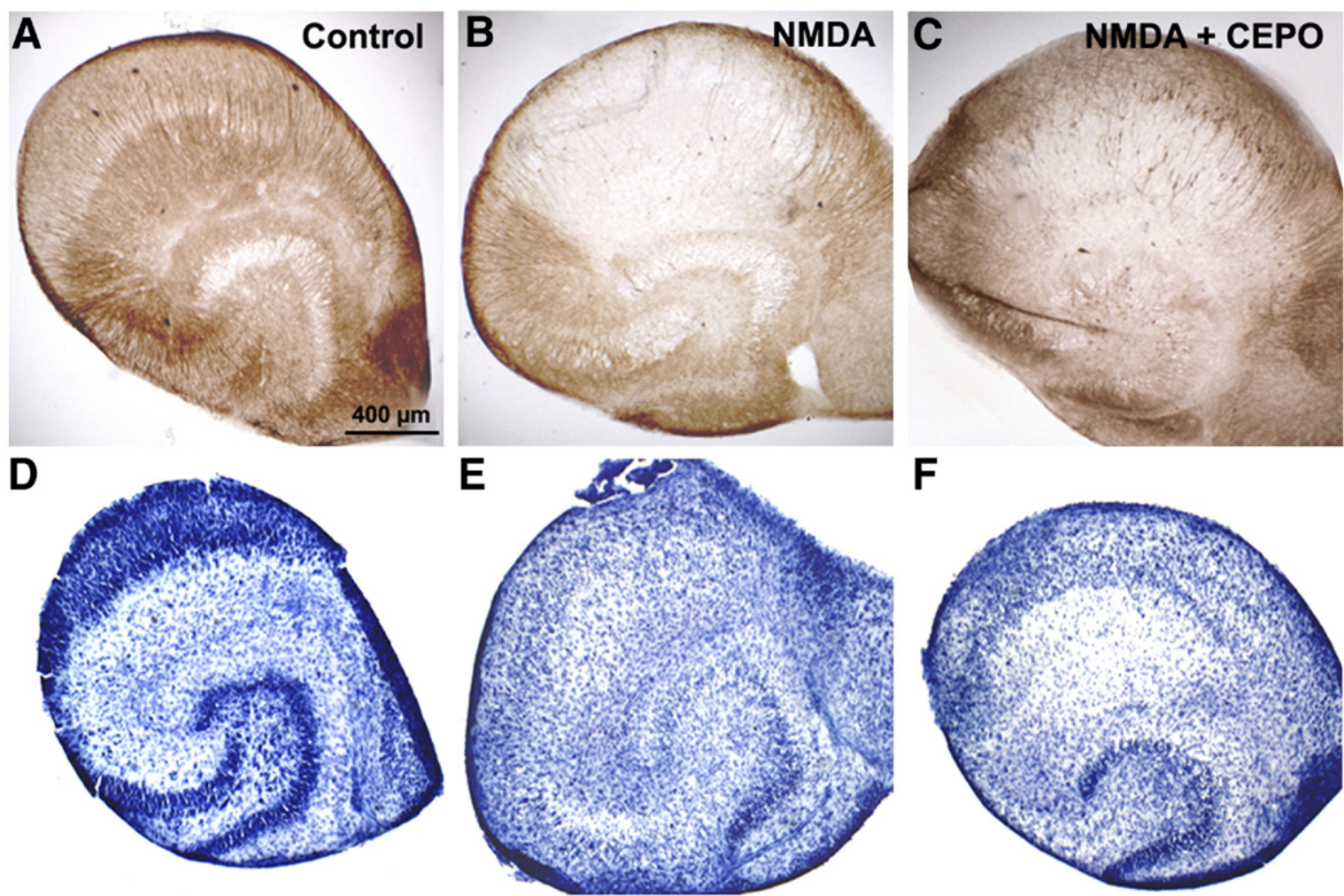

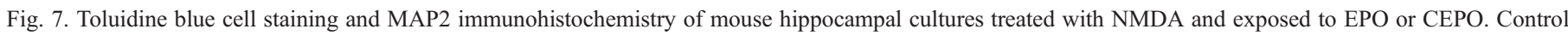

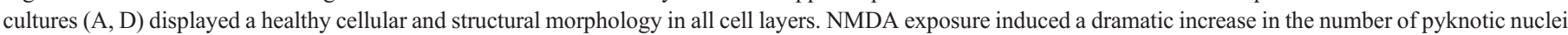

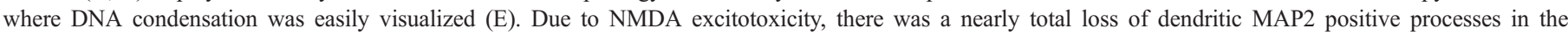

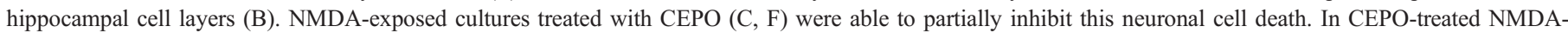
lesioned cultures, some scattered healthy nuclei could be observed (F).

degeneration (Bonde et al., 2002). Hippocampal cultures exposed to OGD (Figs. 6B; 8E) and NMDA (Figs. 7B; 9A) displayed a significant loss in MAP2 immunoreactivity, particularly in the CA1 region, $24 \mathrm{~h}$ after the insult, while control cultures displayed intact MAP2 immunoreactivity (Figs. 6 and 7A; 8A). Exposure to EPO, $24 \mathrm{~h}$ prior to OGD or NMDA treatment, as well as during the insult and for $24 \mathrm{~h}$ after, reduced the loss of MAP2 when compared to cultures subjected to OGD (Fig. 8F) and NMDA only (Fig. 9B). Furthermore, OGD-lesioned CEPO-treated cultures appeared very similar to control cultures with well-preserved CA1 pyramidal cells with well-preserved dendrites (Figs. 6C; 8G).

\section{Discussion}

The purpose of this study was to evaluate and compare the neuroprotective effects of EPO and its derivate CEPO against OGD and excitotoxic NMDA lesions in mouse hippocampal slice cultures. Experimental in vitro models are often used to study biochemical and morphological changes related to degeneration processes because they allow a more easy and precise control of the extracellular environment compared to in vivo models. Organotypic hippocampal slice cultures offer several advantages in terms of preservation of 3-dimensional structure (Gahwiler, 1984; Stoppini et al., 1991) where the basic neuron-neuron and neuron-glia connections are maintained with normal electrophysiological properties (Blaabjerg et al., 2003; Frotscher et al., 1990; Gahwiler, 1988; Gahwiler et al., 1997; Zimmer and Gahwiler, 1984). For our experiments, mouse hippocampal slice cultures of postnatal brain tissue were established and grown on semiporous membranes, using the method of Stoppini et al. (1991) as modified by Noraberg et al. (1999). In the presently used protocol, EPO and CEPO were applied for $24 \mathrm{~h}$ prior to the lesion, during OGD and $24 \mathrm{~h}$ thereafter or during the $24 \mathrm{~h}$ of NMDA exposure. In this study, the control cultures for both lesion models exhibited very low, non-significant PI uptake. The PI uptake in the sham-OGD cultures was higher than in non-manipulated control cultures. We interpret this as being due to a mild trauma induced by adding the OGD medium on the top of the cultures. Both EPO and CEPO were able to effectively attenuate the neuronal cell death, with CEPO displaying what appeared to be a more general and more efficient neuroprotective effect. When directly comparing the neuroprotective effects of EPO and CEPO on the CA3 and CA1 pyramidal and dentate granule cells layers tested in the two lesion models (OGD and NMDA), CEPO was significantly more efficient for all cell layers in the OGD experiments, but did not reach significant difference from EPO in any of the subfields in the NMDA experiments. In the NMDA lesion model, where CA1 pyramidal cells have been shown to be more susceptible to NMDA excitotoxicity than other hippocampal neurons (Monyer et al., 1994), we observed 

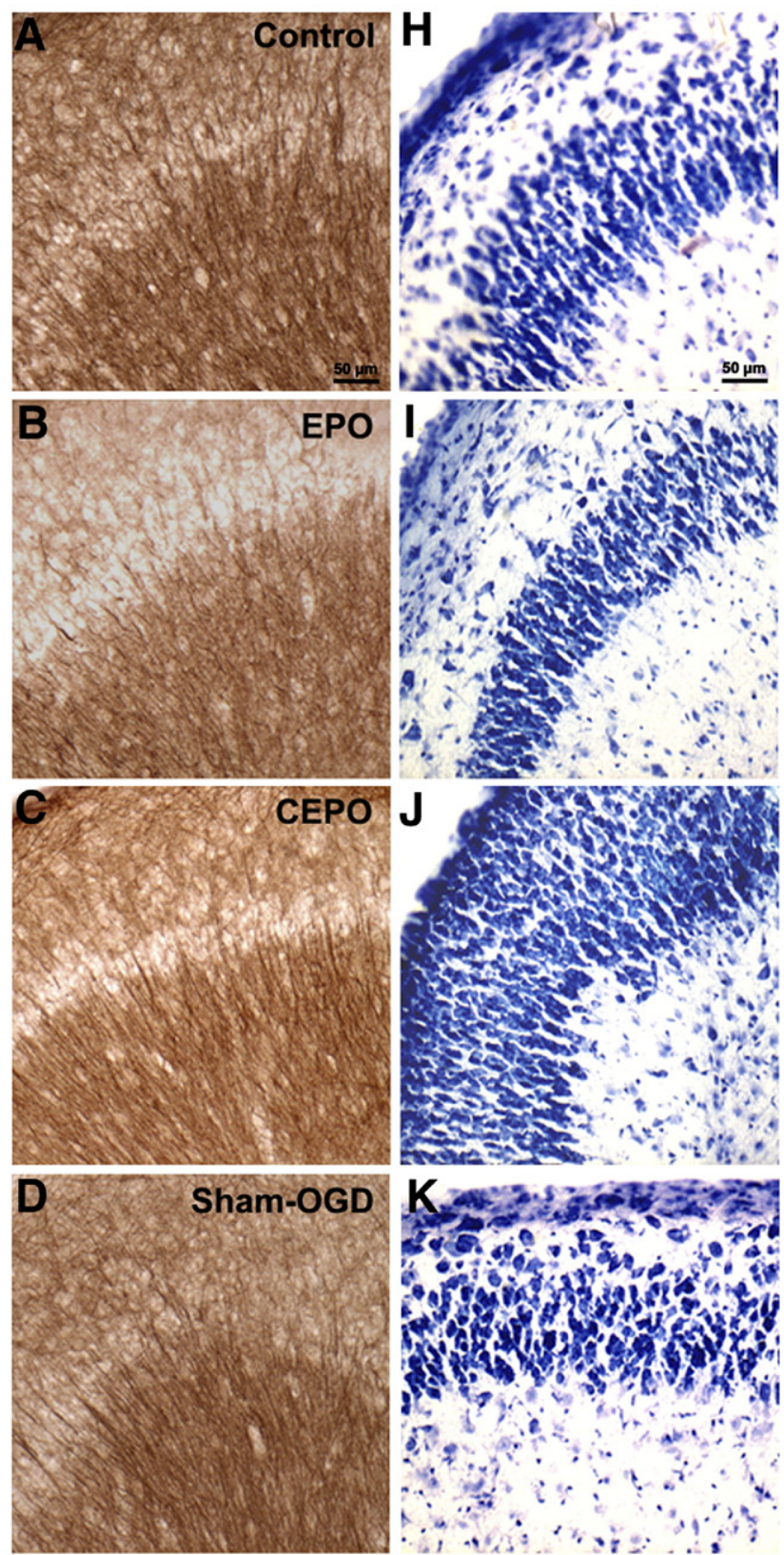
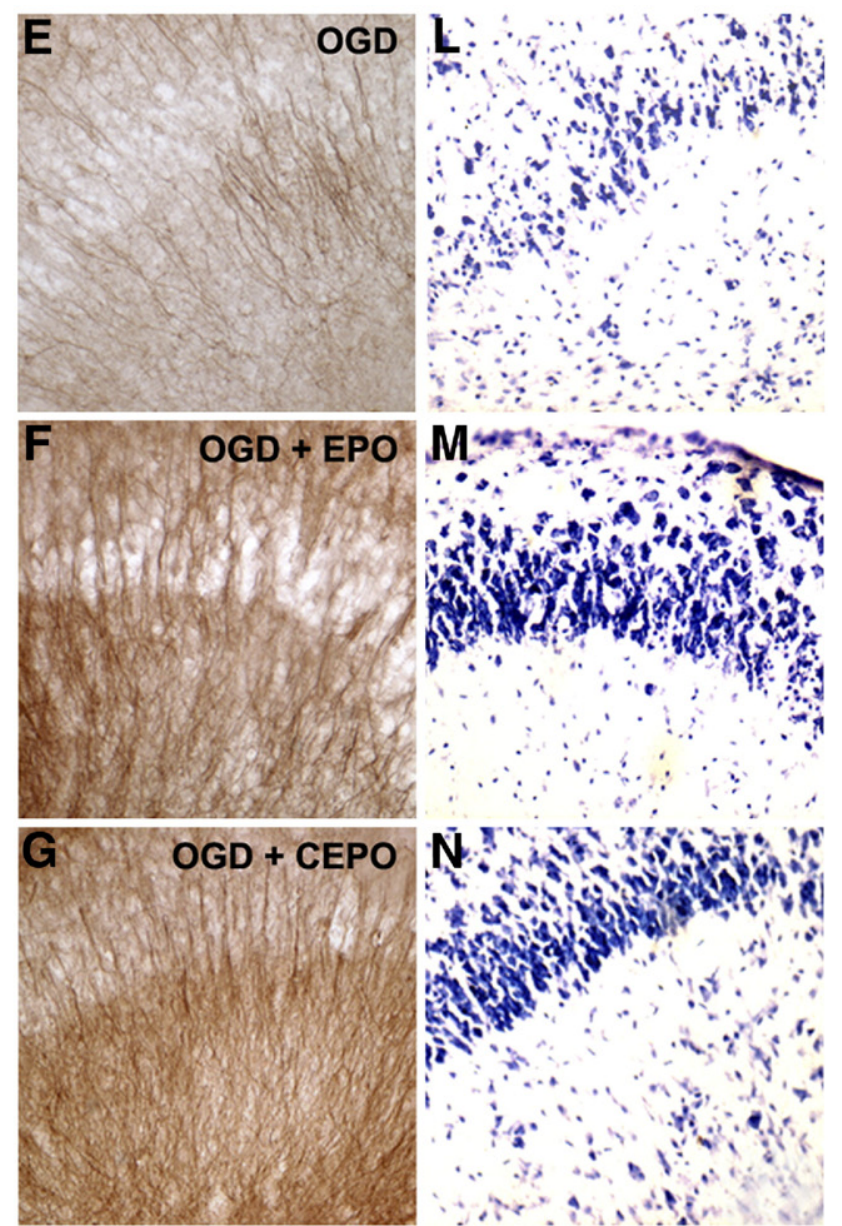

Fig. 8. Immunoreactivity of MAP2 (A-G), an early marker of neuronal degeneration, and TB cell staining (H, N) in control and OGD-exposed mouse hippocampal slice cultures with and without presence of EPO and CEPO. Both control and sham-OGD cultures displayed a healthy morphology (H and K respectively) with dense MAP2 staining of neuronal processes (A and D respectively). Unlesioned EPO (B, I) and CEPO (C, J) treated cultures showed a similar, normal pattern of MAP2 immunoreactivity. In OGD-lesioned cultures, MAP2 immunoreactivity was reduced in particular in the CA1 pyramidal cell layer (E) and there was a significant increase in the number of pyknotic nuclei $(\mathrm{L})$. Both EPO- $(\mathrm{F}, \mathrm{M})$ and CEPO-treated OGD-exposed cultures $(\mathrm{G}, \mathrm{N})$ were able to protect against this loss in MAP2 immunohistochemistry, with CEPO having a better effect than EPO.

that the neuroprotective effect of EPO and CEPO was less strong (for EPO not significantly present) compared to CA3 and dentate gyrus. We anticipate that this difference in neuroprotection between different hippocampal cell layers most likely is due to the stronger severity of the NMDA-induced lesion in $\mathrm{CA} 1$, and not the involvement of different mechanisms of action for the different cell types.

Several studies suggest that the EPO neuroprotective signaling pathways have some similarities to the pathways in erythropoiesis, including activations of Janus-tyrosine kinase 2
(Jak2) (Bittorf et al., 1997; Kawakami et al., 2001), signal transducers and activators of transcription (STATs) (Bittorf et al., 2000; Damen et al., 1995) and of nuclear factor kappaB (NFkB) (Figueroa et al., 2002; Matsushita et al., 2003). When the EPO molecule binds to the EPOR, a dimerization of the receptor occurs with subsequent autophosphorylation of Jak2 and receptor activation. In non-neuronal cells, Jak2 activation conducts the activation of different downstream signaling pathways like Ras/MAPK, PI(3)K and STAT5 (Choi and Rothman, 1990; Ihle et al., 1995). However, this hematopoietic 

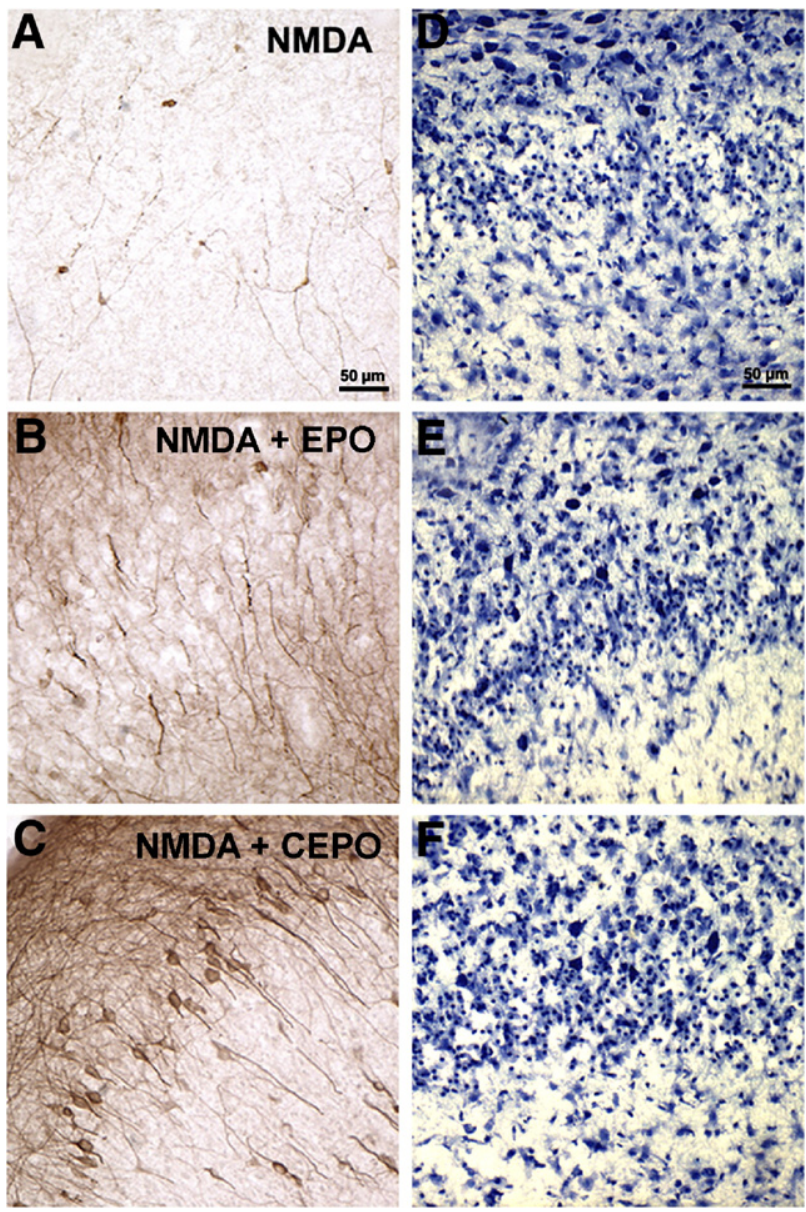

Fig. 9. Immunoreactivity of MAP2 (A-C) and TB cell staining (D-F) in control and NMDA excitotoxically lesioned mouse hippocampal slice cultures with or without EPO or CEPO. NMDA exposure leads to an almost total lost of MAP2 immunoreactivity and an increase in dead or dying cells assessed by TB in particular in the CA1 pyramidal cell layer (A, D) but also in the other cell layers. EPO protected partially this MAP2 loss in all cell layers in excitotoxic lesioned cultures (B, E). CEPO-treated NMDA-lesioned cultures (C, F) displayed a healthier morphology assessed by TB cell staining and where an increase in MAP2 immunoreactivity could be seen when compared to EPO-treated NMDAlesioned cultures

intracellular signaling pathways have been shown to be functional also in neurons (Siren et al., 2001). By inhibiting MAPK or PI(3)K in hypoxia-cell death studies, EPO neuroprotection was abrogated, suggesting a crucial role of these pathways in EPO-induced protection (Siren et al., 2001). The relation between Jak2 and the transcription factor NFkB is well established (Digicaylioglu and Lipton, 2001). EPO exhibits a dose-response increase in nuclear NFkB and a concomitant decrease in cytoplasmatic $\mathrm{NFkB}$, a translocation required for its neuroprotective effect. In addition, phosphorylation of Jak2 is required for $\mathrm{NFkB}$ translocation into the nucleus and EPO neuroprotection in neurons (Digicaylioglu and Lipton, 2001). Recently, it has been shown that EPO variants that do not activate the classical homodimeric EPOR are still neuroprotective (Leist et al., 2004). This is in line with findings that the brain EPOR differs from the one leading to hematopoietic actions regarding affinity for EPO, molecular weight as well as associated proteins (Masuda et al., 1993). The EPOR has been demonstrated to functionally associate with other cytokine receptors such as CD131 (Hanazono et al., 1995; Jubinsky et al., 1997), also known as common $\beta$ receptor ( $\beta c R)$ subunit. The $\beta c R$ is one of the signal transducing subunits shared by the granulocyte-macrophage colony-stimulating factor and the IL-3 and IL-5 receptors (D'Andrea and Gonda, 2000). Experiments with $\beta c R$ knock out mice showed that the $\beta c R$ is not necessary for the process of erythropoiesis, thus non-altered erythrocyte maturation was seen in these knock out mice (Scott et al., 2000). It has been postulated that the tissue protective receptor involved in EPO signaling mechanisms might be the heteroreceptor dimer constituted by the EPOR and the $\beta c R$ subunit (Brines et al., 2004). One may speculate that different neuroprotective activities of EPO and CEPO, as observed here in hippocampal slice cultures, are due to a different activation of such a heteroreceptor by the two ligands. Other explanations are also possible like different rates of diffusion into slice cultures resulting in differences in local concentrations and different surface charges of EPO and CEPO. In order to clarify that, a larger study employing multiple concentrations and time points would be needed. It should be noted, however, that the concentrations of EPO and CEPO used in this study already are 2- to 3-fold higher than concentrations used in monolayer cell culture studies. For in vivo studies, EPO has been used in concentrations up to $5000 \mathrm{U} / \mathrm{kg}$ which is estimated to yield a plasma concentration of approximately $200 \mathrm{U} / \mathrm{ml}$ (Vaziri et al., 1995), which is similar to the concentration used in our experiments.

The exact mechanisms responsible for CEPO neuroprotective effects in vitro still remain to be identified. EPO is a pleiotropic cytokine known to exert its neuroprotection by reducing NO overproduction, inhibiting inflammation and modulating antiapoptotic genes among other functions (Genc et al., 2004a,b). These actions are known to involve several receptors and signaling pathways. Many studies suggest a role of EPOR in tissue protection (Bernaudin et al., 1999; Siren et al., 2001), but the receptor complex mediating EPO hematopoietic effects and EPO neuroprotective actions differs in the affinity for EPO and the associated proteins involved (Masuda et al., 1993). Moreover, CEPO does not seem to bind to the EPOR despite displaying neuroprotective actions (Leist et al., 2004), but Brines et al. (2004) recently reported that using knock out $(\mathrm{KO})$ mice for the $\beta \mathrm{cR}$ subunit the neuroprotective effects of both EPO and CEPO were abolished. In characterizing the EPO molecule, Campana et al. (1998) showed the presence of a region in the EPO molecule, not within the EPOR binding site, which is associated with neuroprotective actions. Studies in PC12 cells show similar affinities of EPO and CEPO for these cells. Although CEPO does not bind to the EPOR, EPO and CEPO seemed to compete for a common binding site in this cell type (Leist et al., 2004). Brana et al. (1999) were the first ones to correlate calpain activity, measured as spectrin cleavage, with membrane integrity assessed by PI uptake. They found the spectrin breakdown products, detected by Western blot, as early as $1 \mathrm{~h}$ after OGD followed by a steady increase for up to $24 \mathrm{~h}$. In accordance with these data, we found an increase 
in the formation of $150 \mathrm{kDa}$ and $145 \mathrm{kDa}$ spectrin cleaved products at $24 \mathrm{~h}$ after $30 \mathrm{~min}$ OGD. This increase was efficiently inhibited by preincubating the hippocampal slices for $24 \mathrm{~h}$ before the OGD with EPO or CEPO, suggesting that one possible mechanism of EPO and CEPO is by prevention of calpain activation.

Although further studies are needed to clarify the mechanisms mediating the neuroprotective effects of CEPO, this compound clearly could be a good candidate for developing new neuroprotective strategies without interfering with the hematopoietic system.

\section{Acknowledgments}

Birthe Jakobsen is gratefully acknowledged for providing the data for the NMDA dose-response experiments. Dorte Bramsen, Randi Godskesen and Karen Rich are gratefully acknowledged for their technical assistance. This work was supported by grants from the Danish MRC to Jens Zimmer and a Danish Research Agency Internationalization Stipend to Maria Montero, obtained through the Danish Stem Cell Research Doctoral School (DASCDOC). Additional financial support was provided by Desirée and Niels Ydes Foundation, Novo Nordisk Foundation, the Nordic Center of Excellence and Fonden til Lægevidenskabens fremme.

\section{References}

Azuma, M., David, L.L., Shearer, T.R., 1991. Cysteine protease inhibitor e64 reduces the rate of formation of selenite cataract in the whole animal. Curr. Eye Res. 10, 657-666.

Bernaudin, M., Marti, H.H., Roussel, S., Divoux, D., Nouvelot, A., Mackenzie, E.T., Petit, E., 1999. A potential role for erythropoietin in focal permanent cerebral ischemia in mice. J. Cereb. Blood Flow Metab. 19, 643-651.

Bernaudin, M., Bellail, A., Marti, H.H., Yvon, A., Vivien, D., Duchatelle, I., Mackenzie, E.T., Petit, E., 2000. Neurons and astrocytes express EPO mRNA: oxygen-sensing mechanisms that involve the redox-state of the brain. Glia. 30, 271-278.

Bittorf, T., Jaster, R., Ludtke, B., Kamper, B., Brock, J., 1997. Requirement for JAK2 in erythropoietin-induced signalling pathways. Cell Signal 9, $85-89$.

Bittorf, T., Sasse, T., Wright, M., Jaster, R., Otte, L., Schneider-Mergener, J., Brock, J., 2000. cDNA cloning and functional analysis of a truncated STAT5a protein from autonomously growing FDCP-1 cells. Cell Signal 12, 721-730.

Blaabjerg, M., Baskys, A., Zimmer, J., Vawter, M.P., 2003. Changes in hippocampal gene expression after neuroprotective activation of group I metabotropic glutamate receptors. Brain Res. Mol. Brain Res. 117, 196-205.

Bonde, C., Noraberg, J., Zimmer, J., 2002. Nuclear shrinkage and other markers of neuronal cell death after oxygen-glucose deprivation in rat hippocampal slice cultures. Neurosci. Lett. 327, 49-52.

Brana, C., Benham, C.D., Sundstrom, L.E., 1999. Calpain activation and inhibition in organotypic rat hippocampal slice cultures deprived of oxygen and glucose. Eur. J. Neurosci. 11, 2375-2384.

Brines, M., Cerami, A., 2005. Emerging biological roles for erythropoietin in the nervous system. Nat. Rev. Neurosci. 6, 484-494.

Brines, M., Grasso, G., Fiordaliso, F., Sfacteria, A., Ghezzi, P., Fratelli, M., Latini, R., Xie, Q.W., Smart, J., Su-Rick, C.J., Pobre, E., Diaz, D., Gomez, D., Hand, C., Coleman, T., Cerami, A., 2004. Erythropoietin mediates tissue protection through an erythropoietin and common beta-subunit heteroreceptor. Proc. Natl. Acad. Sci. U. S. A. 101, 14907-14912.
Buemi, M., Cavallaro, E., Floccari, F., Sturiale, A., Aloisi, C., Trimarchi, M., Grasso, G., Corica, F., Frisina, N., 2002. Erythropoietin and the brain: from neurodevelopment to neuroprotection. Clin. Sci. (LOND). 103, 275-282.

Buemi, M., Caccamo, C., Nostro, L., Cavallaro, E., Floccari, F., Grasso, G., 2005. Brain and cancer: the protective role of erythropoietin. Med. Res. Rev. $25,245-259$.

Campana, W.M., Misasi, R., O’Brien, J.S., 1998. Identification of a neurotrophic sequence in erythropoietin. Int. J. Mol. Med. 1, 235-241.

Choi, D.W., 1995. Calcium: still center-stage in hypoxic-ischemic neuronal death. Trends Neurosci. 18, 58-60.

Choi, D.W., Rothman, S.M., 1990. The role of glutamate neurotoxicity in hypoxic-ischemic neuronal death. Annu. Rev. Neurosci. 13, 171-182.

Chong, Z.Z., Lin, S.H., Kang, J.Q., Maiese, K., 2003. Erythropoietin prevents early and late neuronal demise through modulation of Akt1 and induction of caspase 1, 3, and 8. J. Neurosci. Res. 71, 659-669.

D'Andrea, R.J., Gonda, T.J., 2000. A model for assembly and activation of the GM-CSF, IL-3 AND IL-5 receptors: insights from activated mutants of the common beta subunit. Exp. Hematol. 28, 231-243.

Damen, J.E., Wakao, H., Miyajima, A., Krosl, J., Humphries, R.K., Cutler, R.L., Krystal, G., 1995. Tyrosine 343 in the erythropoietin receptor positively regulates erythropoietin-induced cell proliferation and stat5 activation. EMBO J. 14, 5557-5568.

Davis, L.E., Widness, J.A., Brace, R.A., 2003. Renal and placental secretion of erythropoietin during anemia or hypoxia in the ovine fetus. Am. J. Obstet. Gynecol. 189, 1764-1770.

Digicaylioglu, M., Bichet, S., Marti, H.H., Wenger, R.H., Rivas, L.A., Bauer, C., Gassmann, M., 1995. Localization of specific erythropoietin binding sites in defined areas of the mouse brain. Proc. Natl. Acad. Sci. U. S. A. 92, $3717-3720$

Digicaylioglu, M., Lipton, S.A., 2001. Erythropoietin-mediated neuroprotection involves cross-talk between Jak2 and NF-kappaB signalling cascades. Nature 412, 641-647.

Ehrenreich, H., Degner, D., Meller, J., Brines, M., Behe, M., Hasselblatt, M., Woldt, H., Falkai, P., Knerlich, F., Jacob, S., von Ahsen, N., Maier, W., Bruck, W., Ruther, E., Cerami, A., Becker, W., Siren, A.L., 2004. Erythropoietin: a candidate compound for neuroprotection in schizophrenia. Mol. Psychiatry. 9, 42-54.

Figueroa, Y.G., Chan, A.K., Ibrahim, R., Tang, Y., Burow, M.E., Alam, J., Scandurro, A.B., Beckman, B.S., 2002. NF-kappaB plays a key role in hypoxia-inducible factor-1-regulated erythropoietin gene expression. Exp. Hematol. 30, 1419-1427.

Fisher, J.W., 2003. Erythropoietin: physiology and pharmacology update. Exp. Biol. Med. (Maywood) 228, 1-14.

Frantseva, M.V., Carlen, P.L., El-Beheiry, H., 1999. A submersion method to induce hypoxic damage in organotypic hippocampal cultures. J. Neurosci. Methods 89, 25-31.

Frotscher, M., Heimrich, B., Schwegler, H., 1990. Plasticity of identified neurons in slice cultures of hippocampus: a combined Golgi/electron microscopic and immunocytochemical study. Prog. Brain Res. 83, 323-339.

Gahwiler, B.H., 1984. Development of the hippocampus in vitro: cell types, synapses and receptors. Neuroscience 11, 751-760.

Gahwiler, B.H., 1988. Organotypic cultures of neural tissue. Trends Neurosci. $11,484-489$.

Gahwiler, B.H., Capogna, M., Debanne, D., McKinney, R.A., Thompson, S.M., 1997. Organotypic slice cultures: a technique has come of age. Trends Neurosci. 20, 471-477.

Genc, S., Koroglu, T.F., Genc, K., 2004a. Erythropoietin and the nervous system. Brain Res. 1000, 19-31.

Genc, S., Koroglu, T.F., Genc, K., 2004b. Erythropoietin as a novel neuroprotectant. Restor. Neurol. Neurosci. 22, 105-119.

Hanazono, Y., Sasaki, K., Nitta, H., Yazaki, Y., Hirai, H., 1995. Erythropoietin induces tyrosine phosphorylation of the beta chain of the GM-CSF receptor. Biochem. Biophys. Res. Commun. 208, 1060-1066.

Ihle, J.N., Witthuhn, B.A., Quelle, F.W., Yamamoto, K., Silvennoinen, O., 1995. Signaling through the hematopoietic cytokine receptors. Annu. Rev. Immunol. 13, 369-398. 
Jubinsky, P.T., Krijanovski, O.I., Nathan, D.G., Tavernier, J., Sieff, C.A., 1997. The beta chain of the interleukin-3 receptor functionally associates with the erythropoietin receptor. Blood 90, 1867-1873.

Juul, S.E., Anderson, D.K., Li, Y., Christensen, R.D., 1998. Erythropoietin and erythropoietin receptor in the developing human central nervous system. Pediatr. Res. 43, 40-49.

Juul, S.E., Yachnis, A.T., Rojiani, A.M., Christensen, R.D., 1999. Immunohistochemical localization of erythropoietin and its receptor in the developing human brain. Pediatr. Dev. Pathol. 2, 148-158.

Kawakami, M., Sekiguchi, M., Sato, K., Kozaki, S., Takahashi, M., 2001. Erythropoietin receptor-mediated inhibition of exocytotic glutamate release confers neuroprotection during chemical ischemia. J. Biol. Chem. 276, 39469-39475.

Leist, M., Ghezzi, P., Grasso, G., Bianchi, R., Villa, P., Fratelli, M., Savino, C., Bianchi, M., Nielsen, J., Gerwien, J., Kallunki, P., Larsen, A.K., Helboe, L., Christensen, S., Pedersen, L.O., Nielsen, M., Torup, L., Sager, T., Sfacteria, A., Erbayraktar, S., Erbayraktar, Z., Gokmen, N., Yilmaz, O., Cerami-Hand, C., Xie, Q.W., Coleman, T., Cerami, A., Brines, M., 2004. Derivatives of erythropoietin that are tissue protective but not erythropoietic. Science 305, 239-242.

Marti, H.H., Wenger, R.H., Rivas, L.A., Straumann, U., Digicaylioglu, M., Henn, V., Yonekawa, Y., Bauer, C., Gassmann, M., 1996. Erythropoietin gene expression in human, monkey and murine brain. Eur.J. Neurosci. 8, 666-676.

Martin, S.J., O’Brien, G.A., Nishioka, W.K., Mcgahon, A.J., Mahboubi, A., Saido, T.C., Green, D.R., 1995. Proteolysis of fodrin (non-erythroid spectrin) during apoptosis. J. Biol. Chem. 270, 6425-6428.

Masuda, S., Nagao, M., Takahata, K., Konishi, Y., Gallyas Jr., F., Tabira, T., Sasaki, R., 1993. Functional erythropoietin receptor of the cells with neural characteristics. Comparison with receptor properties of erythroid cells. J. Biol. Chem. 268, 11208-11216.

Matsushita, H., Johnston, M.V., Lange, M.S., Wilson, M.A., 2003. Protective effect of erythropoietin in neonatal hypoxic ischemia in mice. Neuroreport 14, 1757-1761

Monyer, H., Burnashev, N., Laurie, D.J., Sakmann, B., Seeburg, P.H., 1994. Developmental and regional expression in the rat brain and functional properties of four NMDA receptors. Neuron. 12, 529-540.

Nagai, A., Nakagawa, E., Choi, H.B., Hatori, K., Kobayashi, S., Kim, S.U., 2001. Erythropoietin and erythropoietin receptors in human CNS neurons, astrocytes, microglia, and oligodendrocytes grown in culture. J. Neuropathol. Exp. Neurol. 60, 386-392.

Nath, R., Raser, K.J., Mcginnis, K., Nadimpalli, R., Stafford, D., Wang, K.K., 1996a. Effects of ice-like protease and calpain inhibitors on neuronal apoptosis. Neuroreport 8, 249-255.

Nath, R., Raser, K.J., Stafford, D., Hajimohammadreza, I., Posner, A., Allen, H., Talanian, R.V., Yuen, P., Gilbertsen, R.B., Wang, K.K., 1996b. Nonerythroid alpha-spectrin breakdown by calpain and interleukin 1 betaconverting-enzyme-like protease(s) in apoptotic cells: contributory roles of both protease families in neuronal apoptosis. Biochem. J. 319 (PT 3), $683-690$.

Noraberg, J., Kristensen, B.W., Zimmer, J., 1999. Markers for neuronal degeneration in organotypic slice cultures. Brain Res. Brain Res. Protoc. 3 , 278-290.

Ruscher, K., Freyer, D., Karsch, M., Isaev, N., Megow, D., Sawitzki, B., Priller, J., Dirnagl, U., Meisel, A., 2002. Erythropoietin is a paracrine mediator of ischemic tolerance in the brain: evidence from an in vitro model. J. Neurosci. 22, 10291-10301.

Saido, T.C., Sorimachi, H., Suzuki, K., 1994. Calpain: new perspectives in molecular diversity and physiological-pathological involvement. Faseb. J. $8,814-822$.

Sasaki,R., 2003.Pleiotropic functions of erythropoietin. Intern. Med.42,142-149.

Scott, C.L., Robb, L., Papaevangeliou, B., Mansfield, R., Nicola, N.A., Begley, C.G., 2000. Reassessment of interactions between hematopoietic receptors using common beta-chain and interleukin-3-specific receptor beta-chainnull cells: no evidence of functional interactions with receptors for erythropoietin, granulocyte colony-stimulating factor, or stem cell factor. Blood 96, 1588-1590.

Siman, R., Noszek, J.C., 1988. Excitatory amino acids activate calpain I and induce structural protein breakdown in vivo. Neuron. 1, 279-287.

Siren, A.L., Fratelli, M., Brines, M., Goemans, C., Casagrande, S., Lewczuk, P., Keenan, S., Gleiter, C., Pasquali, C., Capobianco, A., Mennini, T., Heumann, R., Cerami, A., Ehrenreich, H., Ghezzi, P., 2001. Erythropoietin prevents neuronal apoptosis after cerebral ischemia and metabolic stress. Proc. Natl. Acad. Sci. U. S. A. 98, 4044-4049.

Stoppini, L., Buchs, P.A., Muller, D., 1991. A simple method for organotypic cultures of nervous tissue. J. Neurosci. Methods 37, 173-182.

Vaziri, N.D., Zhou, X.J., Smith, J., Oveisi, F., Baldwin, K., Purdy, R.E., 1995. In vivo and in vitro pressor effects of erythropoietin in rats. Am. J. Physiol. 269, F838-F845.

Wang, K.K., Yuen, P.W., 1994. Calpain inhibition: an overview of its therapeutic potential. Trends Pharmacol. Sci. 15, 412-419.

Zimmer, J., Gahwiler, B.H., 1984. Cellular and connective organization of slice cultures of the rat hippocampus and fascia dentata. J. Comp. Neurol. 228, $432-446$. 